\title{
Negative refraction metamaterial with low loss property at millimeter wave spectrum
}

\author{
B. A. F. Esmail ${ }^{1}$, H. A. Majid², F. A. Saparudin 3 , M. Jusoh ${ }^{4}$, A. Y. Ashyap 5 , \\ Najib Al-Fadhali6, M. K. A. Rahim ${ }^{7}$ \\ ${ }^{1,5,6}$ Faculty of Electrical \& Electronic Engineering, Universiti Tun Hussein Onn Malay sia, Malay sia \\ ${ }^{2,3}$ Faculty of Engineering Technology, Universiti Tun Hussein Onn Malay sia, Malaysia \\ ${ }^{4}$ School of Computer and Communication Engineering, Universiti Malay sia Perlis (UniM AP), Malay sia \\ ${ }^{7}$ Faculty of Electrical Engineering, Universiti Teknologi Malay sia, Malay sia
}

\begin{tabular}{|c|c|}
\hline Article Info & ABSTRACT \\
\hline Article history: & \multirow{10}{*}{$\begin{array}{l}\text { The design of the millimetre-wave (MMW) metamaterials (MMs) unit } \\
\text { cell operates at } 28 \mathrm{GHz} \text { is presented and numerically investigated. } \\
\text { The proposed structure composed of a modified split ring resonator (MSRR) } \\
\text { printed on both sides of the substrate layer. Popular MM structures } \\
\text { such as S-shape, G-shape, and } \Omega \text {-shape are adjusted to operate at the } 28 \mathrm{GHz} \\
\text { for comparison purpose. MSRR achieves a wide bandwidth of } 1.1 \mathrm{GHz} \\
\text { in comparison with its counterparts at the resonance frequency. Moreover, } \\
\text { the proposed structure presents very low losses by providing the highest } \\
\text { transmission coefficient, } \mathrm{S}_{21} \text {, at the corresponding frequency region. } \\
\text { The radiation loss is substantially suppressed and the negativity } \\
\text { of the constitutive parameters of the proposed MM structure is maintained. } \\
\text { By applying the principle of the electromagnetically induced transparency } \\
\text { (EIT) phenomenon, the MSRR unit cell induces opposite currents on both } \\
\text { sides of the substrate which leads to cancelling out the scattering fields } \\
\text { and suppresses the radiation loss. The constitutive parameters of the MM } \\
\text { structures are retrieved using well-known retrieval algorithm. The proposed } \\
\text { structure can be used to enhance the performance of fifth-generation (5G) } \\
\text { antenna such as the gain and bandwidth. }\end{array}$} \\
\hline Received Oct 22, 2019 & \\
\hline Revised Dec 30, 2019 & \\
\hline Accepted Jan 27, 2020 & \\
\hline Keywords: & \\
\hline & \\
\hline Metamaterial (MMs) & \\
\hline Millimeter-wave (MMW) & \\
\hline Negative refraction & \\
\hline Radiation loss & \\
\hline
\end{tabular}

This is an open access article under the $\underline{C C B Y-S A}$ license.

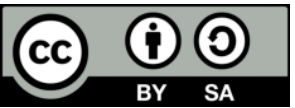

\section{Corresponding Author:}

\section{H. A. Majid,}

Faculty of Engineering Technology,

Universiti Tun Hussein Onn Malaysia,

86400 Parit Raja, Johor, Malaysia.

Email: mhuda@uthm.edu.my

\section{INTRODUCTION}

Metamaterials (MMs) are engineered materials with an extraordinary property not usually found in nature such as the negative permittivity $\varepsilon$, permeability, $\mu$ and the refractive index, $\mathrm{n}$ [1]. These unique properties were predicted theoretically in 1967 by the Russian scientist Victor Veselago. After 29 years, the experimental verification of the negative $\varepsilon$ and $\mu$ had been introduced by Pendry in 1996 [2-3]. Subsequently, different types of artificial MMs unit cells with different shapes had been introduced, such as the SRRs [4], complementary CSRRs [5], broad-side-coupled SRRs [6], fishnet structure [7], $\Omega$-shape [8]. G-shape [9] and S-shape [10]. MMs with unique electromagnetic properties had been proposed for a wide range of applications. However, these artificial materials suffer from serious impairments that restrict their range of applications and late enable MM based devices such as tight bandwidth and the losses. MM suffers from high losses when the operating frequency is increased to the higher range such as in the MMW 
frequency range [11]. These inherent losses can introduce a serious problem in losing the unusual electromagnetic properties of the MMs. MMs losses are induced by radiation and ohmic losses [12]. The radiation loss is the major component of losses in the MMs [13]. In this regard, low loss MMs structures are in high demand to integrate the MMs with practical devices, especially at high-frequency range. In the literature, various techniques had been proposed to compensate the MMs losses at different frequency bands. For example, using the RLC resonance circuit model of the MMs structures to reduce the losses by increasing quality factor (Q- factor) value and thereby compensate the MMs losses [14], tailoring geometry of MM unit cell [15, 16], and integrate gain materials or active devices with MM unit cell [17]. The most common technique is using the electromagnetically induced transparency phenomenon (EIT). This method provides low loss and maintains the negativity of constitutive parameters of the MMs structures [18-20]. On the other hand, the large swathes of the spectrum, high speed and high channelcapacity offered by MMW frequency range make this spectrum appropriate option for different applications like automotive radars, Gbit communications, and medical imaging sensors [21-23]. Recently, the MMW frequency range is proposed for future $5 \mathrm{G}$ communications. The tremendous available amount of MMW band is utilized to increase the capacity of the communication system[23].

In this paper, the MSRR MMs unit cell that operates at the MMW frequency range is designed and numerically investigated. For comparis on purposes, three common MMs structures which are the $S$-shape, G-shape, and $\Omega$-shape are optimized to operate at $28 \mathrm{GHz}$. The proposed MM structure shows a very high performance than its counterparts at the corresponding frequency region by providing the highest trans mission coefficient, S21. In addition, the negativity of the constitutive parameters of the MM structures is maintained at the specified frequency range.

\section{THE PROPOSED MM STRUCTURE}

The schematic view of the proposed MSRR, S-shape, G-shape, and $\Omega$-shape unit cells are illustrated in Figure 1(a)-(d). The double split ring metallic shapes of the MSRR structure are printed on both sides of the substrate. The proposed MSRR structure and other known unit cells are constructed onto Rogers RT5880 substrate with the dielectric constant of 2.2, tangent-loss of 0.0009 , and thickness of $0.508 \mathrm{~mm}$. The metallic layer is the lossy metal copper with a conductivity of $5.8 \times 10^{\wedge} 7 \mathrm{~S} / \mathrm{m}$ and the thickness of $0.035 \mathrm{~mm}$. The dimensions of the structure are $\mathrm{L}=2 \mathrm{~mm}, \mathrm{~W}=2 \mathrm{~mm}, \mathrm{~L} 1=1.8 \mathrm{~mm}, \mathrm{~W} 1=1.9 \mathrm{~mm}, \mathrm{~L} 3=0.9, \mathrm{G}=0.1 \mathrm{~mm}$. The length (L) and width (W) of other unit cells are given in the caption of Figure 1. The boundary conditions are applied to induce the electromagnetic wave (EM) and to retrieve the permeability, permittivity and refractive index of the MSRR MM structure. In this work, the electric field and magnetic field are assigned along the y-axis and $\mathrm{x}$-axis, respectively. The electromagnetic wave is guided through the z-direction. The CST Microwave Studio is used to perform the numerical simulation.

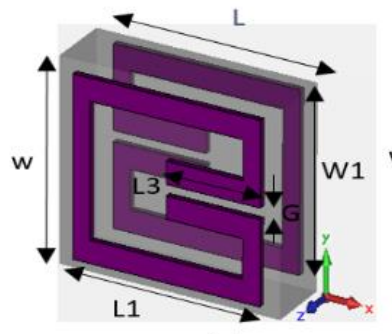

(a)

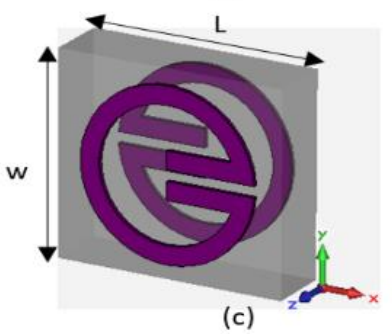

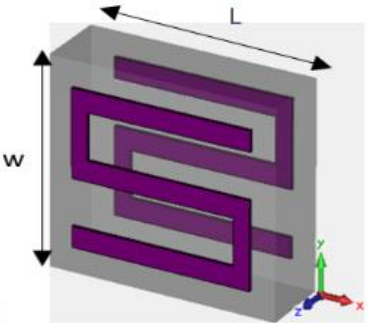

(b)

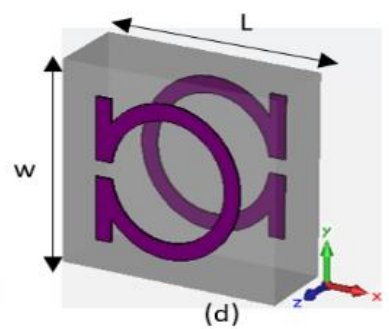

Figure 1. The schematic view of the MM structures, (a) The proposed MSRR, (b) S-shape $(2 \times 2.9 \mathrm{~mm})$, (c) G-shape $(2 \times 2.3 \mathrm{~mm})$, (d) $\Omega$-shape $(4 \times 3.7 \mathrm{~mm})$ 


\section{S-PARAMETERS PERFORMANCE}

The proposed MSRR, S-shape, G-shape, and $\Omega$-shape unit cells are designed and adjusted to operate at $28 \mathrm{GHz}$. The reflection coefficients, $\mathrm{S}_{11}$, of the proposed MSRR and the other three-unit cells are depicted in Figure 2. At $28 \mathrm{GHz}$, the MSRR structure realize the best performance in terms of reflection coefficient and bandwidth over other MM structures. This structure achieves a reflection coefficient of $-36 \mathrm{~dB}$ and the bandwidth of $1.1 \mathrm{GHz}$. The lowest bandwidth is achieved by the S-shape unit cell with a bandwidth of $0.2 \mathrm{GHz}$. In terms of bandwidth, the proposed MSRR unit cell presents a wider bandwidth as compared to the other unit cells in spit of the drawback of the tight bandwidth of MMs.

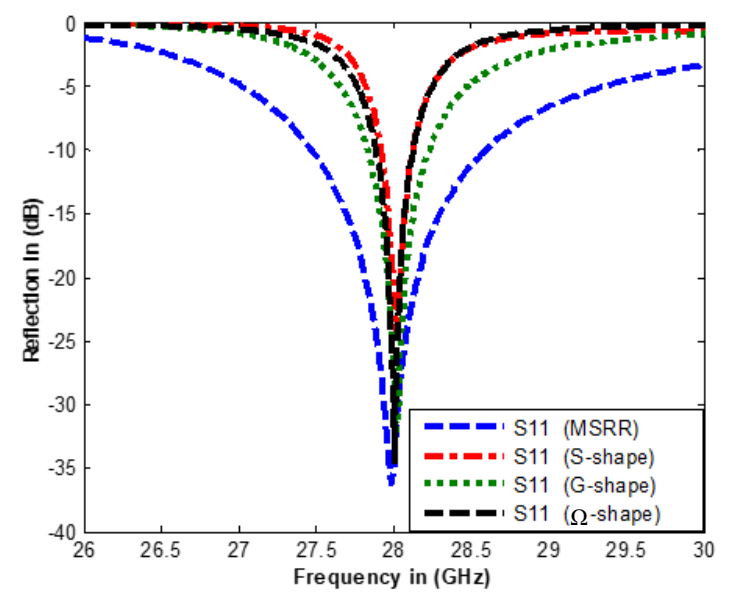

Figure 2. Simulated reflection coefficient results of the proposed MSRR, S-shaped, G-shape, and $\Omega$-shape unit cells

The MMs losses turn out to be a serious issue which limits their practical applications, especially at the MMW spectrum. To reduce the inherent loss in the MMs, the radiation loss should be suppressed. In this subsection, the dominant component in the MM losses, radiation loss, of the MSRR and the other three MM unit cells are analyzed, investigated and minimized at $28 \mathrm{GHz}$. The transmission coefficient of the proposed MSRR, S-shape, G-shape, and $\Omega$-shape unit cells at $28 \mathrm{GHz}$ are plotted in Figure 3. It is noticeable that the loss achieved by MSRR unit cell is very small in comparison with its counterparts where it achieves $-0.1 \mathrm{~dB}$. This low loss achievement is due to tailoring the parameters of the structure at the simulation stage. The highest loss is presented by S-shaped resonator with approximately $-0.5 \mathrm{~dB}$. In order to understand the reduction mechanism of the $\mathrm{MM}$ radiation loss, the induced surface current distribution based on the electromagnetically induced transparency (EIT) phenomenon is used.

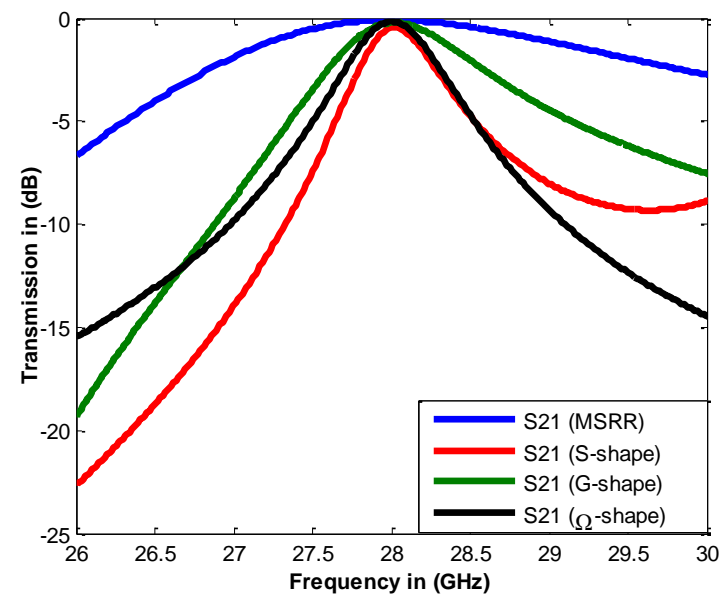

Figure 3. Simulated transmission coefficient results of the proposed MSRR, S-shaped, G-shape, and $\Omega$-shape unit cells 
The induced surface currents of the MSRR structure and other unit cells at $28 \mathrm{GHz}$ are depicted in Figure 4. The induced surface current of the MSRR structure produces a circulating current on the front and back sides of the unit cell through the strip that extends to the middle of the structure which leads to the magnetic dipole response as shown in Figure 4(a). However, due to the excitement of the magnetic dipole response, the electric dipole response is also simultaneously excited, which leads to induce significant radiation losses. By applying the opposite currents through the double rings on both sides of the substrate, where one of the double rings is the inverse of the other, the induced currents cancel out on both sides of the structure, subsequently suppressing the radiation loss. In specific, the modification in the unit cell parameters through the simulation display the antiparallel currents at both sides of the unit cell which lead to cancelling out the scattering fields on both sides, thus induces the EIT effect and greatly suppresses the radiation loss. Moreover, one can observe that the surface current distribution of the MSRR is fully uniform over the whole MM structure, which supports the low loss attribute of the MM structure [11].

The induced current of the $\mathrm{S}$-s hape unit cell is not uniform over both sides as compared to the MSRR structure, thereby the loss is extremely high. The electric dipole moment is introduced by the horizontal lines of the S-shape, subsequently increasing the radiation loss of this structure as shown in Figure 4(b). The low loss mechanism of MSRR can be applied for G-shape unit cell where the currents on both sides of the G-shape cancel out each other and thereby reducing the radiation loss as depicted in Figure 4(c). The loss of this structure is relatively low in comparison to S-shape unit cells. However, the surface currents are not sufficiently u niform over the whole structure and this introduces a bit high loss as compared to our proposed structure. The surface current distribution is uniform over the $\Omega$-shape structure as shown in Figure 4(d). Thus the loss is low in comparison with S-shape.

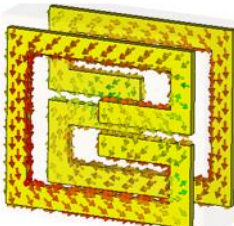

(a)

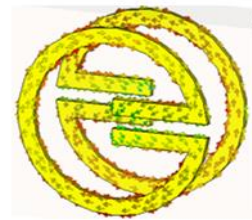

(c)
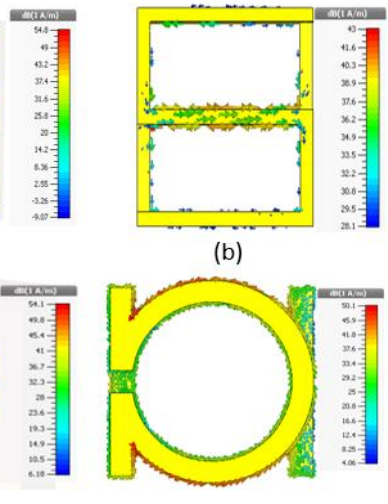

(d)

Figure 4. The induced surface current of both sides of the unit cells at $28 \mathrm{GHz}$, (a) the proposed MSRR,

(b) S-shape, (c) G-shape, (d) $\Omega$-shape

\section{RETRIEVE THE CONSTITUTIVE PARAMETERS}

The properties of the four MM structures such as complex reflection and transmission have been extracted using CST microwave studio. Then the constitutive parameters can be retrieved using a well-known algorithm which is a robust method [24]. In this algorithm, the properties of the four structures which extracted from the simulation are used to calculate the index of refraction, $n_{\text {eff }}$ and impedance $z_{\text {eff }}$. The relation between the s-parameters and the effective impedance, $z_{e f f}$ is given by:

$$
\begin{aligned}
& S_{11}=\frac{R_{Z}\left(1-e^{i 2 n k d}\right)}{1-R_{Z}^{2} e^{i 2 n k d}} \\
& S_{11}=\frac{\left(1-R_{Z}^{2}\right) e^{i 2 n k d}}{1-R_{Z}^{2} e^{i 2 n k d}}
\end{aligned}
$$

where $R_{Z}=\mathrm{z}-1 / \mathrm{z}+1, \quad k_{0}$ and $d$ are the wavenumber and the thickness of the MM structure, repectively. By inverting (1) and (2), the $z_{e f f}$ and $n_{\text {eff }}$ are obtained based on the S-parameters as follows [25]:

$$
Z_{e f f}=\sqrt{\frac{\left(1+S_{11}\right)^{2}-S_{21}^{2}}{\left(1-S_{11}\right)^{2}-S_{21}^{2}}}
$$




$$
n_{e f f}=\frac{1}{k d}\left[\left\{\operatorname{Img}\left(\ln \left(e^{i n k d}\right)\right)+2 m \pi\right\}-i \operatorname{Re}\left(\ln \left(e^{i n k d}\right)\right)\right]
$$

where,

$$
\begin{aligned}
& e^{i n k d}=\left[\left(\frac{1}{2 S_{21}}\right)\left(1-{S_{11}}^{2}+S_{21}{ }^{2}\right)\right] \mp \\
& i \sqrt{1-\left[\left(\frac{1}{2 S_{21}}\right)\left(1-{S_{11}}^{2}+S_{21}{ }^{2}\right)\right]^{2}}
\end{aligned}
$$

The effective permittivity and effective permeability can becalculated using the following expression:

$$
\varepsilon_{\text {eff }}=n z \text { and } \mu_{\text {eff }}=n / z
$$

The real parts of the permittivity $\varepsilon$, permeability $\mu$ and the refractive index, $n$ of the proposed MSRR, S-shape, G-shape, and $\Omega$-shape unit cells are plotted in Figures 5(a)-(d). As can be seen from Figure, all structures present a negative index of refraction at the resonance frequency with different ranges. The transmission coefficient peaks of the structures in the region where all the real parts of the constitutive parameters are negative. Our proposed unit cell unveils a very large negative refractive indexes bandwidth which extended over the two regions above and below the resonance frequency. The range of the first region, below the resonant frequency, is extended from $23.8 \mathrm{GHz}$ up to $28 \mathrm{GHz}$ and $28.3 \mathrm{GHz}$ up to $29 \mathrm{GHz}$ for the region above the resonance frequency. The negative refractive index of the S-shaped resonator is extended above and below the resonance frequency as well, but with a small range of the negativity. However, G-shape and $\Omega$-shape unit cells introduce a large bandwidth of the negative refractive index either below or above the resonance frequency. The performance of the four MM structures is compared and tabulated in Table 1.

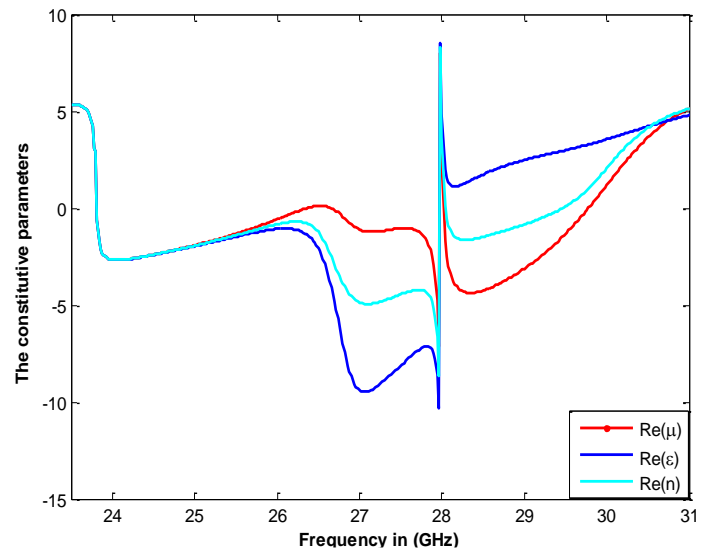

(a)

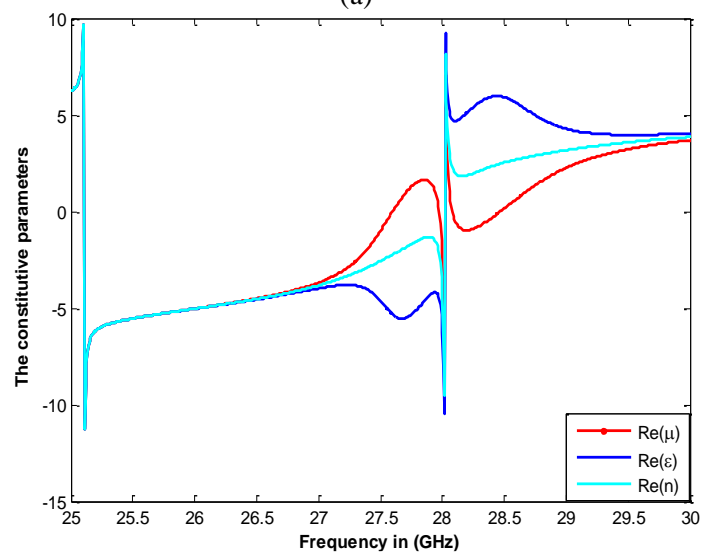

(c)

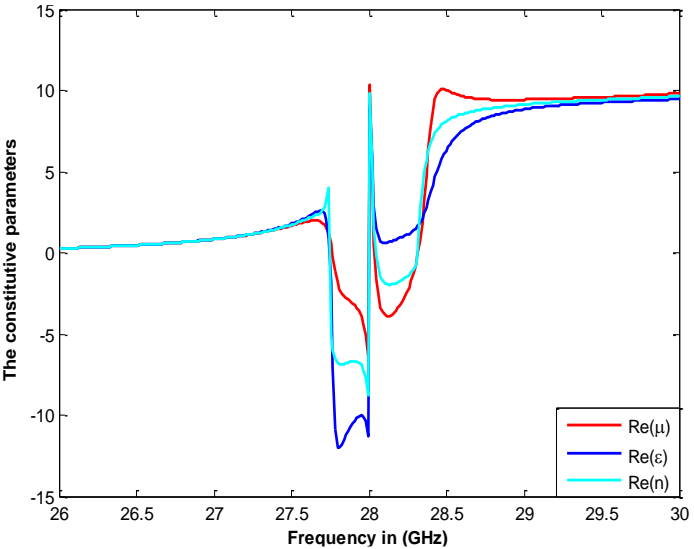

(b)

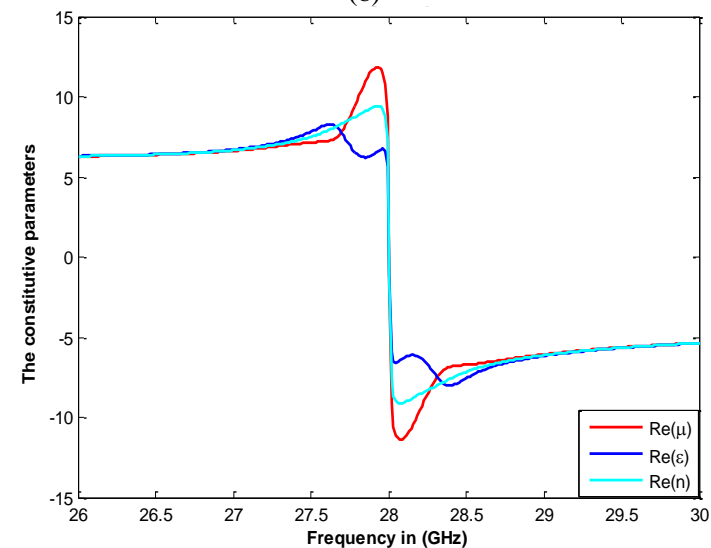

(d)

Figure 5. The real parts of the constitutive parameters at $28 \mathrm{GHz}$, (a) the proposed MSRR unit cell, (b) S-shape, (c) G-shape, (d) $\Omega$-shape 
Table 1. The performance comparis on of the four MM structures

\begin{tabular}{lcccc}
\hline MM structure & Proposed MSRR & S-shape & G-shape & $\Omega$-shape \\
\hline S1 $1(\mathrm{~dB})$ & -36 & -24 & -32 & -34 \\
S21 $(\mathrm{dB})$ & -0.1 & -0.5 & 0.3 & -0.2 \\
Bandwidth $(\mathrm{GHz})$ & 1.1 & 0.2 & 0.4 & 0.22 \\
Range of negative refraction $(\mathrm{GHz})$ & 4.2 & 0.23 & 2.85 & 4 \\
\hline
\end{tabular}

\section{CONCLUSION}

In conclusion, the low loss MSSR structure operating at MMW frequency range is proposed and numerically characterized. The MSRR is composed of modified double metallic rings printed on both sides of the substrate which operates at $28 \mathrm{GHz}$. For comparis on purpose, $\mathrm{S}$-shape, G-shape, and $\Omega$-shape unit cells are optimized to operate at $28 \mathrm{GHz}$. Despite the common drawback of the narrow bandwidth of the MMs, the proposed unit cell achieves a wide bandwidth of 1.1 GHz. Moreover, the proposed MM structure shows very high performance in comparis on with its counterparts at the resonance frequency by providing the lowest loss, $-0.1 \mathrm{~dB}$. EIT phenomenon is induced by modifying the MM structure to apply the opposite curre nts on both sides of the substrate which lead to cancelling out the scattering fields. Subsequently, the major component of the MMs losses which is the radiation loss is greatly suppressed. Moreover, the surface current distribution of the MSRR is fully uniform over the whole structure, which supports the low loss attribute of the MM structure. The constitutive parameters are extracted using a well-known algorithm and the negative constitutive parameters are maintained at the resonance frequency. The propos ed MSRR unit cell displays a wide bandwidth of the negative refractive index which extended above and below the resonance frequency. The proposed structure has been investigated through the simulation. This study recommends as a future work test the same structure through the fabrication and measurement. MSRR structure can be utilized to enhance the gain and bandwidth of $5 \mathrm{G}$ antenna.

\section{ACKNOWLEDGEMENTS}

This work was supported by Research Management Centre, Universiti Tun Hussein Onn Malaysia (UTHM) under Grant (Vote No: / CRG K034, FRGS 1647).

\section{REFERENCES}

[1] J. P. Barrett, et al., "Design and Full Characterization of Planar Active Magnetic RF Metamaterials," IEEE Antennas and Wireless Propagation Letters, vol. 14, pp.943-946, 2015.

[2] V. G. Veselago, "The electrodynamics of substances with simultaneously negative values of $\varepsilon$ and $\mu$," Soviet physics uspekhi, vol. 10, pp. 509, 1968 .

[3] J. B. Pendry, et al., "Low frequency plasmons in thin-wire structures," Journal of Physics: Condensed Matter, vol. 10, pp. 4785, 1998.

[4] R.A. Shelby, et al., "Experimental verification of a negative index of refraction," Science, vol. 292, pp. 77-79, 2001.

[5] J. Naqui, et al., "Modeling split-ring resonator (SRR) and complementary split-ring resonator (CSRR) loaded transmission lines exhibiting cross-polarization effects," IEEE Antennas and Wireless Propagation Letters, vol. 12, pp. 178-181.2013

[6] J. Wang, et al., "A tunable left-handed metamaterial based on modified broadside-coupled split-ring resonators," Progress In Electromagnetics Research, vol. 6, pp.35-45, 2009.

[7] K. B. Alici, and E. Ozbay, "A planar metamaterial: Polarization independent fishnet structure," Photonics and Nanostructures-Fundamentals and Applications, vol. 6, pp. 102-107, 2008.

[8] L. Zhaofeng, et al., "Retrieval of effective parameters for bianisotropic metamaterials with omega shaped metallic inclusions," Photonics and Nanostructures-Fundamentals and Applications, vol. 10, pp. 329-336, 2012.

[9] A. Dadgarpour, et al., "Millimeter-wave high-gain SIW end-fire bow-tie antenna," IEEE Transactions on Antennas and Propagation, vol. 63, pp. 2337-2342, 2015.

[10] M.F. Khan, and M. J. Mughal. "Tunable metamaterials by varying the inductance and capacitance of S-shaped resonator," 3rd IEEE International Symposium on Microwave, Antenna, Propagation and EMC Technologies for Wireless Communications. 2009.

[11] L. Zhu, et al., "Low-loss magnetic metamaterial at THz frequencies by suppressing radiation losses," IEEE Transactions on Terahertz Science and Technology, vol. 13, pp. 805-11,2013.

[12] T. Shaw, and D. Mitra, "Design of miniaturized, low-loss and flexible multi-band metamaterial for microwave application," Appl Phys A, vol. 124, pp.348, 2018.

[13] A. N. Lagarkov, et al., "Losses in metamaterials: Restrictions and benefits," Physica B: Condensed Matter, vol. 405, pp. 2925-2929, 2010.

[14] Y. Fan, et al., "Low-loss and high-Q planar metamaterial with toroidal moment," Physical Review B., vol. 87, no. 11, pp. 115417, Mar 2013. 
[15] B. A. Esmail, et al., "Novel Metamaterial Structures with Low Loss at Millimeter Wave Frequency Range," Indonesian Journal of Electrical Engineering and Computer Science, vol. 10, pp. 641-647, 2018.

[16] Z. H. Jiang, et al., "Tailoring dispersion for broadband low-loss optical metamaterials using deep-subwavelength inclusions," Scientific reports, vol. 3, pp. 1571, 2013.

[17] Z. G. Dong, et al., "Optical loss compensation in a bulk left-handed metamaterial by the gain in quantum dots," Applied Physics Letters, vol. 96, pp. 044104, 2010.

[18] X. JunáHe, and C. Huiá Zhao, "A low-loss electromagnetically induced transparency (EIT) metamaterial based on coupling between electric and toroidal dipoles," RSC Adv., vol. 7, pp. 55897-55904, 2017.

[19] H. M. Li, et al., "Low-loss metamaterial electromagnetically induced transparency based on electric toroidal dipolar response," Appl Phys Lett., vol. 106, pp.083511, 2015.

[20] B. A. Esmail, et al., "Dual mode modified double square ring resonator structure at $76 \mathrm{GHz}$," Microw Opt Technol Lett, vol. 61, pp. 1678-1682, 2019.

[21] J. Hasch, et al., "Millimeter-wave technology for automotive radar sensors in the $77 \mathrm{GHz}$ frequency band," IEEE Trans. Microw. Theory Techn., vol. 60, pp. 845-860, 2012.

[22] S. Shahramian, et al., "A 16-element W-band phased-array transceiver chipset with flip-chip PCB integrated antennas for multi-gigabit wireless data links," IEEE Trans. Microw. Theory Techn., vol. 66, pp. 3389-3402, 2018.

[23] B. Tianyang, et al., "Coverage and rate analysis for millimeter-wave cellular networks," IEEE Transactions on Wireless Communications, vol. 14, pp. 1100-1114, 2015.

[24] X. Chen, et al. "Robust method to retrieve the constitutive effective parameters of metamaterials," Physical Review E, vol. 70, no. 1,pp. 016608, 2004.

[25] P. Markoš, et al., "Transmission properties and effective electromagnetic parameters of double negative metamaterials," Opt. express, vol. 11, pp.649-661, 2003.

\section{BIOGRAPHIES OF AUTHORS}

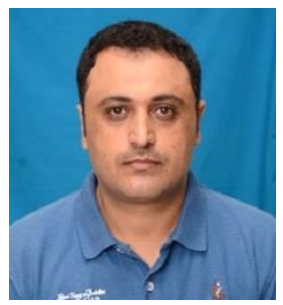

Bashar Ali Esmail received the B Eng. degree in Electrical Engineering (Telecommunications) with honours from Ibb University-Yemen, in 2008. He then obtained his M.Eng (Electrical Engineering) in 2016, at Universiti Tun Hussein Onn Malay sia. He is currently a on going PhD in Electrical Engineering at Faculty of Electrical and Electronic Engineering Universiti Tun Hus sein Onn Malaysia. His research interest includes the areas of design of metamaterials structure, milimter wave antenna and reconfigurable antenna.

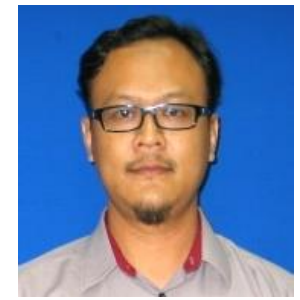

Huda A Majid received the B Eng. degree in Electrical Engineering (Telecommunication) from Universiti Teknologi Malaysia, in 2007. He then obtained his M.Eng in 2010 and PhD degrees in Electrical Engineering in 2013, at Universiti Teknologi Malaysia. He is currently a lecturer in the Department of Electrical Engineering Technology, Faculty of Engineering Technology, Universiti Tun Hussein Onn Malaysia. His research interest includes the areas of design of microstrip antennas, small antennas, Reconfigurable antennas, metamaterials structure, metalaterial antennas and millimeter wave antennas. He has published over 100 articles in journals and conference papers.
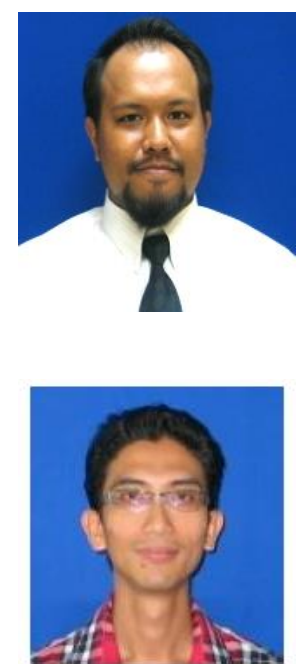

Faiz Asraf Saparudin received his Bachelor B.Sc. in Electrical Engineering (Telecommunication) with First Class Honours from Universiti Teknologi Malay sia in 2010 and received WAMY Academic Excellence Award in the same year. Ph.D. degree in Electrical Engineering (Telecommunication) from the Universiti Teknologi Malaysia in 2015. He is currently a Faculty Member in Fakulti Teknologi Kejuruteraan, Universiti Tun Hussein Onn Malaysia.His current research interests include radio resource management, distributed algorithms, nature-inspired techniques, multiagent system and game theoretic approach for nextgeneration mobile network.

Samsul Haimi Bin Dahlan received the Bachelor's degree in Engineering from the Universiti Kebangsaan of Malaysia, Bangi, Malaysia, in 1999, the Master's degree in engineering from Universiti Teknologi Malaysia, Johor Bahru, Malaysia, in 2005, and the Ph.D. degree from Universite' de Rennes 1, Rennes, France, in 2012. He is currently the Head of the Research Center for Applied Electromagnetics, Universiti Tun Hussein Onn Malaysia (UTHM), Batu Pahat, Malaysia. His research interests include EMC, electromagnetic shielding, bioelectromagnetics, microwave devices, advanced antenna design, material characterization, and computational electromagnetics. Dr. Samsul has published many conference proceedings as well as journal papers in local and international journals. 

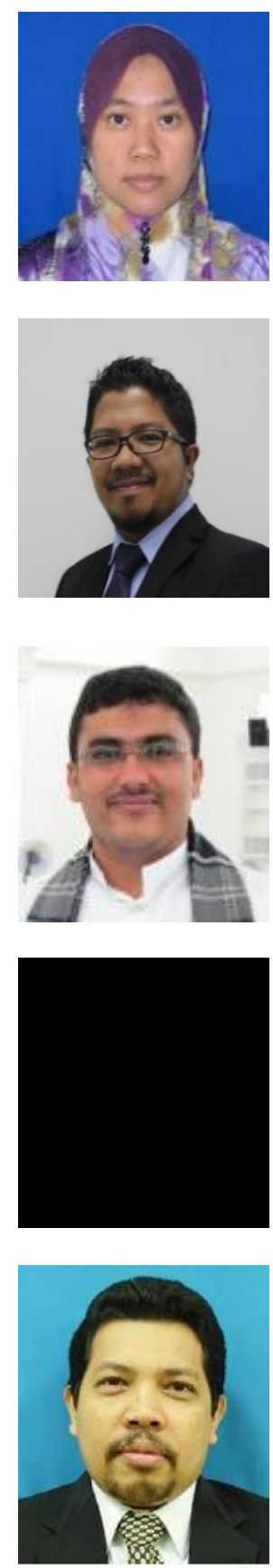

Zuhairiah Zainal Abidin was born in Kuala Lumpur, Malaysia, in 1978. She received the B.Eng. from the Universiti Teknologi Malaysia, in 2001, the M. Eng from the Kolej Universiti Tun Hussein Onn Malaysia, Johor, Malaysia, in 2003, and Ph.D. degree from Bradford University, U.K in 2011. Currently, she was a Senior Lecturer at Universiti Tun Hussein Onn Malay sia. Her current research interests include MIMO antenna design, electromagnetic bandgap (EBG) for wireless and mobile systems and high speed digital circuits and wearable antennas.

Muzammil Jusoh is currently working with Universiti Malaysia Perlis (UniMAP) as an Associates Professor and researcher based in School of Computer and Communication Engineering (SCCE). He has received $\mathrm{PhD}$ in Communication Engineering from UniMAP in 2013. While received MsC. (2010) in Electronic Telecommunication Engineering and Bachelor Degree (2006) in Electrical-Electronic and Telecommunication Engineering from Universiti Teknologi Malaysia (UTM). His research interests include antenna design, reconfigurable beam steering antenna, wearable antenna, MIMO, UWB, wireless on-body communications, in-body communications (implantable antenna), wireless power transfer, RF and microwave communication system.

Adel Y. I. Ashyap received the B.Eng., M.Eng. and Ph.D. degrees in electrical engineering from Universiti Tun Hussein Onn Malay sia, in 2012, 2014, and 2019 respectively. He has authored or co-authored numbers of journals and proceedings. His current research interests include the design of AMC, EBG, wearable, small, and compact antennas for wireless body area net works. He was received the Chancellor Award for his final year project and a number of Gold, Silver, and Bronze medals in international and local competitions.

Najib Al-Fadhali received the B Eng. degree in Electrical Engineering (Telecommunications) with honours from Khartoum Unvirsity-Sudan, in 2008. He then obtained his M.Eng (Electrical Engineering) in 2012, at University of sience and technology in Sudan. Currently, he is a PhD researcher in Electrical and Electronic Engineering, Universiti Tun Hussein Onn Malaysia. His research interest in two area of research which includes the areas of design Frequency reconfigurable SIW antenna as well as the research related to project technology management.

Mohamad Kamal A. Rahim received the B Eng. degree in Electrical and Electronic Engineering from University of Strathcly de, UK, in 1987. In 1989, he joined the Department of Communication Engineering, Faculty of Electrical Engineering Universiti Teknologi Malay sia Kuala Lumpur as an Assistant Lecturer A. He obtained his M. Eng Science from University of New South Wales Australia in 1992 and $\mathrm{PhD}$ degrees in Electrical Engineering from University of Birmingham UK in 2003. He is the Professor in RF and Antenna at Faculty of Electrical Engineering Universiti Teknologi Malaysia. His research interest includes the areas of design of dielectric resonator antennas, microstrip antennas, small antennas, microwave sensors, RFID antennas for readers and tags, Multi-function antennas, microwave cicuits, EBG, artificial magnetic conductors, metamaterials, phased array antennas, computer aided design for antennas and design of millimeter frequency antennas. He has published over 200 articles in journals and conference papers. 